\title{
VARIAÇÕES ANATÔMICAS NA DENTIÇÃO DE CÃES SEM RAÇA DEFINIDA
}

\author{
ANATOMICAL VARIATIONS IN THE DENTITION OF MONGREL DOMESTIC DOGS
}

\author{
Moacir Santos de Lacerda ${ }^{1}$ Simone Tostes de Oliveira ${ }^{2}$ Daise Nunes Queiroz ${ }^{3}$
}

RESUMO

Foi avaliada a dentição de 100 cães adultos sem raça definida, machos e fêmeas, com o objetivo de investigar as variações anatômicas. A ausência congênita de molares foi observada em cães de pequeno porte; a ausência patológica predominou na região dos pré-molares; houve maior frequência de dentes supranumerários na arcada superior, predominando os molares; foram observadas raízes supranumerárias em prémolares e molares superiores e inferiores; e grande número de raízes fusionadas, predominando no segundo pré-molar inferior

Palavras-chave: cão, dente, anatomia.

\section{SUMMARY}

The dentition of 100 adult males and females mongrel dogs were analysed with the objective of investigating the anatomical variations in the dentition. The congenital absence of molars teeth was observed in small dogs. The pathologic absence prevailed in the premolars area. Supemumerary teeth, mainly the molars, were observed in the maxillary arcade. Supemumerary roots on the upper and lower premolars and molars teeth were observed. A large number of fused roots were observed, mainly in the mandibular second premolar teeth.

Key words: $d o g$, tooth, anatomy.

\section{INTRODUÇÃO}

Os livros de anatomia, geralmente, apresentam um padrão uniforme da dentição das espécies, e variações anatómicas, raramente, são mencionadas (VERSTRAETE \& TERPAK, 1997). A fórmula dentária permanente do cão é 2 (I3/3, $\mathrm{Cl} / 1, \mathrm{PM} 4 / 4, \mathrm{M} 2 / 3)=42$. Anomalias dentárias envolvem principalmente a forma (VERSTRAETE \& TERPAK, 1997), o número e a localização dos dentes, sendo mais frequentes em raças braquicefálicas e, raramente, relatadas em raças dolicocefálicas (ANDREWS, 1972; EVANS, 1993; DOLE \& SPURGEON, 1998).

Dentes supranumerários ocorrem quando uma germinação imprópria conduz a uma divisão do germe dental, formando dois dentes, resultando em apinhamento e rotação dos dentes permanentes (HOSKINS, 1993), ou interferindo com a oclusão e saúde periodontal (HOLMSTROM et al., 1998); porém, a distância entre os dentes pode permitir a presença de dentes supranumerários sem a existência de moléstia secundária associada (HARVEY, 1992; HARVEY \& EMILY, 1993). São encontrados com maior frequência na arcada superior (SCHWARZE \& SCHRÕDER, 1984; EVANS, 1993), sendo geralmente unilaterais (EVANS, 1993). Em todas as raças, pré-molares (SCHWARZE \& SCHRÕDER, 1984; HARVEY, 1992; EVANS, 1993; HOSKINS, 1993; DOLE \& SPURGEON, 1998) e incisivos supranumerários (EVANS, 1993; DOLE \& SPURGEON, 1998) são mais comuns que caninos

\footnotetext{
${ }^{1}$ Médico Veterinário, Odontólogo, Mestre, professor Substituto do Departamento de Medicina Animal da Universidade Federal de Uberlândia (UFU). Doutorando do Curso de Pós-Graduação em Medicina Veterinária da UNESP/Jaboticabal. moacir@ufu.br.

${ }^{2}$ Médico Veterinário, Residente do Hospital Veterinário, UFU.

${ }^{3}$ Acadêmica do Curso de Medicina Veterinária, UFU.
} 
ou molares (DOLE \& SPURGEON, 1998), sendo os incisivos supranumerários comuns em raças braquicefálicas (HARVEY \& EMILY, 1993). O prémolar supranumerário apresenta-se tipicamente com uma única raiz e distal ao canino, sendo praticamente indistinguível em tamanho e forma do pré-molar permanente típico (DOLE \& SPURGEON, 1998). Quando houver espaço, um quarto dente molar inferior pode ocorrer (St. CLAIR, 1975).

Num estudo em Greyhounds, DOLE \& SPURGEON (1998) observaram que os dentes supranumerários estavam sempre imediatamente distais ao dente canino, no diastema natural, ou na porção distai final da arcada. Da mesma forma, os dentes estavam presentes onde havia espaço suficiente para erupção completa sem efeitos adversos. Dentes supranumerários em outras localizações resultariam em maloclusões e, provavelmente, há uma seleção natural ou artificial para que isso não ocorra, resultando em ocorrência extremamente rara.

Hipodontia é a ausência de apenas alguns dentes, sendo mais comum em raças pequenas, quando comparada com raças grandes (HARVEY \& EMILY, 1993), e pode ser hereditária (HARVEY, 1992; HARVEY \& EMILY, 1993). A área, mais comum dessa ocorrência em cães é a região dos prémolares (ANDREWS, 1972; HARVEY, 1992) e molares (ANDREWS, 1972).

As anormalidades que podem ser observadas na forma do dente incluem a geminação, que é a divisão de um único broto dental, resultando em uma única raiz com duas coroas; a fusão de dentes com junção de dois brotos dentais, normalmente, separados; a dilaceração, que representa uma curvatura anormal da raiz; as raízes supranumerárias e as pérolas de esmalte, que são áreas de esmalte formadas numa raiz que impedem a fixação periodontal normal (HOSKINS, 1993).

O desvio no número normal de raízes, fusão das raízes ou do dente completo são raramente encontrados (EVANS, 1993). Um dente molar com uma única raiz pode desenvolver uma raiz sulcada ou até duas raízes. Nos dentes com três raízes, duas delas podem fundir-se. As duas raízes de um prémolar rostral podem unir-se retendo um sulco vertical (St. CLAIR, 1975).

As variações anatômicas são de pouca importância clínica. Ocasionalmente, uma raiz supranumerária ou uma coroa malformada podem desencadear um distúrbio no contorno da gengiva, predispondo à doença periodontal. Variações anatômicas se tornam importantes, no entanto, se procedimentos dentários como exodontia e endodontia forem planejados (VERSTRAETE \& TERPAK, 1997; HOLMSTROM et al., 1998).

O objetivo do presente trabalho foi verificar a prevalência de variações anatômicas na dentição em uma população de cães sem raça definida.

\section{MATERIAL E MÉTODO}

Foram utilizados 100 crânios de caninos adultos, machos e fêmeas, sem raça definida, com apenas a dentição permanente presente na cavidade oral. O material foi obtido de cadáveres cuja morte ou eutanásia não incluía razões de patologias dentárias. Os crânios foram preparados conforme técnica convencional de maceração. Todos os dentes foram cuidadosamente identificados e extraídos de seus alvéolos de forma que suas raízes permanecessem intactas. Os dentes foram analisados macroscopicamente quanto ao número, forma $\mathrm{e}$ posicionamento. Não foram feitas radiografias.

Foi aplicado o teste estatístico do Quiquadrado da independência entre dois atributos (tipos de dente $\mathrm{x}$ alteração) em nível de significância de $5 \%$.

\section{RESULTADOS E DISCUSSÃO}

O cão foi escolhido para este trabalho por ser o animal de maior rotina na clínica veterinária para procedimentos odontológicos e, assim sendo, com maior probabilidade de complicações durante este atendimento em decorrência de alterações anatômicas dentárias.

A idade e o sexo dos animais não interferiram nos dados coletados, pois foram utilizados, no experimento, animais adultos e com apenas a dentição permanente na cavidade oral. Foram utilizados animais sem raça definida pela facilidade de obtenção para estudo, e por ser de maior número o atendimento na clínica de odontologia do Hospital Veterinário da Universidade Federal de Uberlândia. Pode-se, em outros estudos, comparar os resultados deste trabalho com os de trabalhos utilizando animais de raça definida.

A técnica convencional de maceração foi eficaz na preparação dos crânios estudados.

Foram estudados 4190 dentes num total de 100 cães. O número estudado diferiu do número esperado (4200), devido à ausência congénita ou patológica de 37 dentes, e à presença de 27 dentes supranumerários. Os resultados estão dispostos nas tabelas 1,2 e 3 .

Dentes supranumerários: dois cães apresentaram um incisivo superior permanente supranumerário, que se encontrava alinhado aos demais, sem perda de osso alveolar e sem reabsorção das raízes. Os incisivos supranumerários foram observados em

Ciência Rural, v. 30, n. 4, 2000. 
animais mesaticefálicos, e não em braquicefálicos, como seria esperado, segundo HARVEY \& EMILY (1993). molares extras sem distúrbios oclusais ou apinhamento. Dois cães apresentaram bilateralmente um molar superior supranumerário distai ao segundo

Tabela 1 - Número de cães sem raça definida apresentando alteraç̃̃es dentárias, Uberlândia, 1998.

\begin{tabular}{|c|c|c|c|c|c|c|c|}
\hline Dente & $\begin{array}{c}\text { Fusão de } \\
\text { Raízes }\end{array}$ & Birradiculares & Trirradiculares & Quadrirradiculares & $\begin{array}{l}\text { Ausência } \\
\text { Congênita }\end{array}$ & Reabsorção Óssea & Supranumerários \\
\hline IS & - & - & - & - & - & 1 & 2 \\
\hline 1PMS & - & - & - & - & - & 2 & 5 \\
\hline 2PMS & 3 & - & - & - & - & 5 & - \\
\hline 3PMS & 1 & - & 4 & - & - & 5 & - \\
\hline $2 \mathrm{MS}$ & 12 & - & - & 1 & 1 & - & - \\
\hline $3 \mathrm{MS}^{*}$ & - & - & - & - & - & - & 2 \\
\hline IPMI & - & - & - & . & - & 1 & 2 \\
\hline 2PMI & 34 & - & . & - & . & 5 & - \\
\hline 3PMI & - & - & 1 & - & - & 1 & - \\
\hline 4PMI & 1 & - & 1 & - & - & 1 & - \\
\hline $2 \mathrm{MI}$ & 1 & - & 2 & - & - & . & - \\
\hline 3MI & - & 6 & - & - & 2 & - & - \\
\hline $4 \mathrm{MI}^{*}$ & - & - & - & - & - & - & 8 \\
\hline TOTAL & 52 & 6 & 8 & 1 & 3 & 21 & 19 \\
\hline
\end{tabular}

*Os dentes foram assim classificados por apresentarem-se imediatamente distais ao $2 \mathrm{MS}$ e $3 \mathrm{MI}$, respectivamente.

IS - incisivo superior; PM - pré-molar; $\mathrm{M}$ - molar; $\mathrm{S}$ - superior; I - inferior.

$\mathrm{X}^{2}=279,25(\mathrm{P}<0,001)$. Existe diferença altamente significativa entre as freqüuências das alterações ocorridas em diferentes dentes.

Cinco cães apresentaram um dente imediatamente distai ao canino superior, sendo que em três deles o dente era bilateral. Dois cães apresentaram unilateralmente um pré-molar inferior supranumerário. Todos os pré-molares supranumerários localizavam-se imediatamente distais ao dente canino, sendo indistinguíveis em tamanho e forma do pré-molar permanente típico, coincidindo com os resultados encontrados por DOLE \& SPURGEON (1998), e em seu diastema natural. Segundo HARVEY \& EMILY (1993), crânios dolicocefálicos podem acomodar pré- molar. Oito cães apresentaram um dente distal ao terceiro molar inferior, com formato semelhante a este, porém menor, e em três desses cães a alteração era bilateral. Segundo St. CLAIR (1975), um quarto dente molar inferior poderia ocorrer quando houvesse espaço, no entanto, o que se notou no presente trabalho foi que, em alguns cães, não havia esse espaço e o dente supranumerário provocou apinhamento. Foi observada maior frequência de dentes supranumerários na arcada superior, concordando com os estudos de SCHWARZE \& SCHRÕDER, (1984), EVANS (1993), e DOLE \& SPURGEON (1998). Apesar de incisivos e

Tabela 2 - Número e porcentagem de alteraçōes da arcada dentária superior de 100 cães sem raça definida, Uberlândia, 1998.

\begin{tabular}{|c|c|c|c|c|c|c|}
\hline Dente & $\begin{array}{c}\text { Raízes } \\
\text { Fusionadas }\end{array}$ & Trirradiculares & Quadrirradiculares & Ausência congênita & Ausência Patológica & $\begin{array}{c}\text { Dentes } \\
\text { Supranumerários }\end{array}$ \\
\hline IS & - & - & - & - & $3(0,5 \%)$ & $2(0,33 \%)$ \\
\hline 1PMS & - & - & - & - & $2(1 \%)$ & $8(4 \%)$ \\
\hline 2PMS & $4(2 \%)$ & - & - & - & $9(4,5 \%)$ & - \\
\hline 3PMS & $1(0,5 \%)$ & $8(4 \%)$ & - & - & $7(3,5 \%)$ & - \\
\hline $2 \mathrm{MS}$ & $20(10 \%)$ & - & $1(0,5 \%)$ & $2(1 \%)$ & - & - \\
\hline $3 \mathrm{MS}^{*}$ & - & - & - & - & - & $4(2 \%)$ \\
\hline TOTAL & $25(1,25 \%)$ & $8(0,4 \%)$ & $1(0,05 \%)$ & $2(0,1 \%)$ & $21(1,05 \%)$ & $14(0,7 \%)$ \\
\hline
\end{tabular}

*Os dentes foram assim classificados por apresentarem-se imediatamente distais ao $2 \mathrm{MS}$

IS - incisivo superior; PM - pré-molar; $\mathrm{M}$ - molar; $\mathrm{S}$ - superior; I - inferior.

$\mathrm{X}^{2}=122,48(\mathrm{P}<0,001)$. Existe diferença altamente significativa entre as frequiências das alteraçōes ocorridas em diferentes dentes. 
Tabela 3 - Número e porcentagem de alteraçōes da arcada dentária inferior de 100 cães sem raça definida, Uberlândia, 1998.

\begin{tabular}{|c|c|c|c|c|c|c|}
\hline Dente & $\begin{array}{c}\text { Raízes } \\
\text { Fusionadas }\end{array}$ & Birradiculares & Trirradiculares & $\begin{array}{l}\text { Ausência } \\
\text { Congênita }\end{array}$ & $\begin{array}{l}\text { Ausência } \\
\text { Patológica }\end{array}$ & $\begin{array}{c}\text { Dentes } \\
\text { Supranumerários }\end{array}$ \\
\hline lPMI & - & - & - & - & $1(0,5 \%)$ & $2(1 \%)$ \\
\hline 2PMI & $53(26,5 \%)$ & - & - & - & $7(3,5 \%)$ & - \\
\hline 3PMI & - & - & $1(0,5 \%)$ & - & $1(0,5 \%)$ & - \\
\hline 4PMI & $2(1 \%)$ & - & $1(0,5 \%)$ & - & $1(0,5 \%)$ & - \\
\hline $2 \mathrm{MI}$ & $1(0,5 \%)$ & - & $4(2 \%)$ & - & - & - \\
\hline $3 \mathrm{MI}$ & - & $8(4 \%)$ & - & $4(2 \%)$ & - & - \\
\hline $4 \mathrm{MI}^{*}$ & - & - & - & - & - & $11(5,5 \%)$ \\
\hline TOTAL & $56(2,54 \%)$ & $8(0,36 \%)$ & $6(0,27 \%)$ & $4(0,18 \%)$ & $10(0,45 \%)$ & $13(0,59 \%)$ \\
\hline
\end{tabular}

*Os dentes foram assim classificados por apresentarem-se imediatamente distais ao $3 \mathrm{MI}$

IS - incisivo superior; PM - pré-molar; $M$ - molar; $S$ - superior; I - inferior.

$X^{2}=257,49(P<0,001)$. Existe diferença altamente significativa entre as frequiências das alterações ocorridas em diferentes dentes.

pré-molares serem esperados com certa frequência (HARVEY, 1992; EVANS, 1993; HOSKINS, 1993; DOLE \& SPURGEON, 1998), observou-se um maior número de molares supranumerários.

Ausência congénita: dois cães miniaturas apresentaram ausência congênita do terceiro molar inferior esquerdo e direito, e um deles apresentou, também, ausência congênita dos segundos molares superiores, e a maxila estendia-se apenas até o primeiro molar, discordando de HARVEY (1992) para o qual a área mais comum de hipodontia é a região dos pré-molares, mas concordando com ANDREWS (1972) que cita a região dos molares como uma das mais afetadas. Segundo HARVEY \& EMILY (1993), a hipodontia é mais comum em cães pequenos, o que também foi observado no presente trabalho. Como o exame foi limitado à inspeção visual, radiografias poderiam revelar a presença de dentes não erupcionados, porém esse fato seria improvável, visto que não havia osso suficiente para comportar o dente em questão. Foi encontrada maior frequência de dentes supranumerários, quando comparada com hipodontia, concordando com as afirmações de ANDREWS (1972).

Ausência patológica (reabsorção óssea do alvéolo): vinte e um cães apresentaram ausência patológica do dente e, com exceção de um animal que apresentava a reabsorção óssea na região dos incisivos, todos os outros apresentaram reabsorção na área dos pré-molares, sendo a região dos segundos pré-molares superiores e inferiores as mais afetadas. Segundo LAWSON et al. (1 960), o primeiro pré-molar é um dente pequeno e, geralmente, é perdido precocemente. Segundo
HERNADEZ (1995, apud GIOSO, 1998), existe um importante volume fornecido pelas raízes dentais dos pré-molares em comparação com a massa total da mandíbula. Esses fatores podem explicar a reabsorção óssea observada na região dos prémolares em adição que qualquer ataque ao periodonto de sustentação (fase aguda da doença periodontal), com perda óssea, mesmo pequena, seria suficiente para promover mobilidade dentária e, conseqüentemente, perda desses elementos dentários.

Raízes supranumerárias: em seis cães o terceiro molar inferior era birradicular, sendo a alteração bilateral em dois deles (Figura IA). Segundo St. CLAIR (1975), um dente molar com uma única raiz pode desenvolver uma raiz sulcada ou até duas raízes. Quatro cães apresentaram o terceiro pré-molar superior bilateralmente trirradicular, sendo a raiz supranumerária a palatina (Figura 1 E). Verificou-se a presença de um terceiro pré-molar inferior (Figura $1 \mathrm{~F}$ ) e um quarto prémolar inferior trirradiculares. Dois cães apresentaram bilateralmente o segundo molar inferior com três raízes (Figura 1B). Em um cão, o segundo molar superior apresentava quatro raízes. Raízes supranumerárias foram observadas em prémolares e molares superiores e inferiores. Essa avaliação toma-se importante ao se programar procedimentos exodônticos e endodônticos, pois a permanência de uma raiz fraturada ou não submetida a tratamento endodôntico pode ter consequências graves, como dor, inflamação e reação periosteal.

Raízes fusionadas: trinta e quatro cães

Ciência Rural, v. 30, n. 4, 2000. 
apresentaram fusão das raízes do segundo pré-molar inferior (Figura 1C) e, em dezenove desses, essa

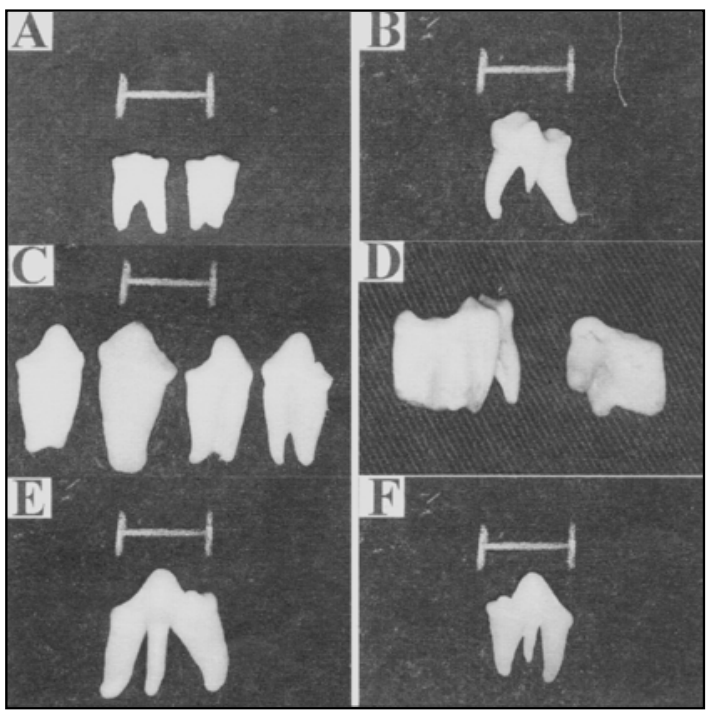

Figura 1 - A: terceiro molar inferior de cão, apresentando-se birradicular; B: segundo molar inferior de cão, apresentando-se trirradicular; $\mathrm{C}$ : segundo pré-molar inferior de cão, apresentando raízes fusionadas; D: segundo molar superior de cão, apresentando raízes fusionadas; E: terceiro pré-molar superior de cão, apresentando-se trirradicular; F: terceiro pré-molar de inferior de cão, apresentando-se trirradicular. Escala $10 \mathrm{~mm}$.

condição era bilateral, enquanto que apenas três animais apresentavam raízes fusionadas no segundo pré-molar superior, sendo essa alteração bilateral em um. As duas raízes de um pré-molar rostral, segundo St. CLAIR (1975), poderiam unir-se retendo um sulco vertical.

Um cão apresentou fusão de raízes bilateral do quarto pré-molar inferior. Um único cão apresentou raízes fusionadas no terceiro pré-molar superior e no segundo molar inferior. Doze cães apresentaram fusão das raízes vestibulares do segundo molar superior (Figura l D) e, em oito desses cães, a condição era bilateral. A fusão de raízes é considerada de ocorrência rara (EVANS, 1993), porém, foi observada nos pré-molares e molares inferiores e superiores, num total de 81 dentes, o que foi altamente significativo, apresentando maior ocorrência no segundo prémolar inferior (53 dentes). Não foi encontrada nenhuma justificativa para a fusão de raízes, nem para o alto índice encontrado, visto que havia espaço suficiente para o desenvolvimento normal dessas raízes.

\section{CONCLUSÕES}

A partir dos dados obtidos, conclui-se

que:

dentes supranumerários, predominantemente molares, ocorrem mais na arcada superior;

ausência congénita de dentes ocorre na região dos molares, e em cães de pequeno porte; ocorre um número considerável de dentes com raízes fusionadas, com maior incidência no segundo prémolar inferior;

raízes supranumerárias ocorrem em prémolares e molares inferiores e superiores.

\section{AGRADECIMENTO}

Ao Professor Adjunto do Departamento de Zootecnia da UFSM José Henrique Souza da Silva, Zootecnista $\mathrm{PhD}$., pela colaboração na realização dos testes estatísticos.

\section{REFERÊNCIAS BIBLIOGRÁFICAS}

ANDREWS, A.H. A case of partial anodontia in a dog Veterinary Record, Londres, v.90, p.144-145, 1972.

DOLE, R.S., SPURGEON, T.L. Frequency of supranumerary teeth in a dolicocephalic canine breed, the Greyhound American Journal of Veterinary Research, Schaumburg, v.59,n.1,Jan,p.16-17,1998.

EVANS, H.E. Miller's anatomy of the dog. 3 ed. Philadelphia: Saunders, 1993. The digestive apparatus and abdomen: p.385462

HARVEY, C.E. Distúrbios orais, faringeanos e das glândulas salivares. In: ETTINGER, S.J. Tratado de medicina interna veterinária. 3 ed. São Paulo: Manole, 1992. v.3. cap.82. p.1265-1317.

HARVEY, C.E., EMILY, P.P. Small animal dentistry. St. Louis: Mosby, 1993. Cap. 8: Occiusion, oclusive abnormalities, and orthodontic treatment: p.266-269.

HERNADEZ, S.Z. Aspects of dental anatomy of clinical and surgical importance. In: GIOSO, M.A. Análise morfométrica óssea e dental e sua relação com características físicas do cão (Canis Familiaris) como fator predisponente para a doença periodontal. São Paulo, 1998 45p. Tese (Doutorado em Cirurgia) - Faculdade de Medicina Veterinária. E Zootecnia. Universidade de São Paulo, 1998.

HOLMSTROM, S.E, FROST, P., EISNER, E.R. Veterinary dental techniques for the small animal practitioner. 2 ed. Philadelphia: Saunders, 1998. 530p.

HOSKINS, J.D. Pediatria veterinária: cães e gatos até 6 meses de idade. São Paulo: Manole, 1993. Cap.7: O sistema digestivo: p.153-222.

LAWSON, D.D., NIXON, G.S., NOBLE, H.W. et al Dental anatomy and histology of the dog. Research in Veterinary Science, Londres, v.1, n.3, p.201-204,1960.

SCHWARZE, E., SCHRÕDER, L. Compendio de anatomia veterinária. 2 ed. Zaragoza: Acribia, 1984. v.2,313p.

St.CLAIR, L.E. Sistema digestivo do carnívoro. Dentes, to:

Ciência Rural, v. 30, n. 4, 2000. 
GETTY, R. Sisson/ Grossman. Anatomia dos animais domésticos. 5 ed. Rio de Janeiro: Guanabara Koogan, 1975.

v.2. cap.51. p.1443-1464

VERSTRAETE, F.J.M., TERPAK, C.H. Anatomical variations of the domestic cat. Journal of Veterinary Dentistry, Philadelphia, v.14, n.4, Dec, p.137-140,1997.

Ciência Rural, v. 30, n. 4, 2000. 